\title{
Early Detection and Rescue of an Unusual Case of Pediatric Acute Liver Failure Associated with Secondary Hemophagocytic Lymphophagocytosis: Case Report from a Liver Transplant Center in India
}

\author{
${ }^{1}$ Department of Pediatric Gastroenterology, Indraprastha Apollo \\ Hospital, New Delhi, India \\ 2 Department of Pediatric Intensive Care, Indraprastha Apollo \\ Hospital, New Delhi, India \\ ${ }^{3}$ Department of Pediatric Hematooncology, Indraprastha Apollo \\ Hospital, New Delhi, India
}

Richa Mittal $^{1}$ Smita Malhotra ${ }^{1}$ Nameet Jerath ${ }^{2}$ Amita Mahajan $^{3} \quad$ Anupam Sibal $^{1}$

J Child Sci 2021;11:e141-e144.

\begin{abstract}
Address for correspondence Richa Mittal, MBBS, MD, DNB, FPGH, Department of Pediatric Gastroenterology and Hepatology, Indraprastha Apollo Hospital, 2/53/3 Sadar Bazaar, Delhi Cantonment, New Delhi 110010, India (e-mail: richamittal444@gmail.com).
\end{abstract}

\begin{abstract}
Keywords

- acute liver failure

- hemophagocytosis

- pediatrics

Hemophagocytic lymphohistiocytosis $(\mathrm{HLH})$ is a rare, multisystem, potentially fatal clinicopathologic syndrome. $\mathrm{HLH}$ presenting predominantly as pediatric acute liver failure (PALF) has been rarely reported. Early recognition is imperative to initiate life-saving treatment but is often hampered due to the rarity of this syndrome, variable clinical presentations, and nonspecific clinical and laboratory findings. In this article, we reported a case of secondary HLH (H1N1 and RSV positive) presenting as PALF from India. A previously healthy 22-month-old boy presented with fever, vomiting, and altered sensorium for 10 days. He had coagulopathy and deranged liver functions. He was evaluated for underlying etiology and managed on lines of PALF. Due to persistent bicytopenia and excessively high ferritin levels, HLH was strongly suspected though he did not fulfill all clinical criteria for the diagnosis of $\mathrm{HLH}$. Presence of seizures and cerebrospinal fluid analysis was suggestive of central nervous system involvement. There was no evidence of primary $\mathrm{HLH}$ on genetic evaluation. Real-time polymerase chain reaction amplifications were positive for RSV and influenza A H1N1, confirming the causative triggers. After the administration of immunosuppressants and oseltamivir, the patient's symptoms improved dramatically and he recovered completely. To the best of our knowledge, this is the fourth case reported worldwide till date of successful rescue of ALF in a child associated with $\mathrm{HLH}$ completely without resorting to liver transplantation. Clinical vigilance is crucial for possible presence of $\mathrm{HLH}$ with varied initial presentations in PALF despite incomplete diagnostic criteria, with detailed etiological workup for commencing life-saving therapy in time.
\end{abstract}

\section{Introduction}

Hemophagocytic lymphohistiocytosis (HLH) is a potentially fatal syndrome. It is a hyperinflammatory state with hyperse-

received

December 16, 2020 accepted after revision April 10, 2021
DOI https://doi.org/

$10.1055 / \mathrm{s}-0041-1731078$.

ISSN 2474-5871. cretion of cytokines and characterized by the deficient function of natural killer cells and hyperactivation of antigen presenting cells and cytotoxic $\mathrm{T}$ cells. This leads to life-threatening tissue damage and organ failure. ${ }^{1,2}$ Primary or familial HLH is

(c) 2021. The Author(s).

This is an open access article published by Thieme under the terms of the Creative Commons Attribution License, permitting unrestricted use, distribution, and reproduction so long as the original work is properly cited. (https://creativecommons.org/licenses/by/4.0/)

Georg Thieme Verlag KG, Rüdigerstraße 14, 70469 Stuttgart, Germany 
associated with several known genetic mutations and presents usually at an early age (median age $=2.9$ months). Secondary or acquired HLH is triggered by infection, malignancies, autoimmune diseases, and metabolic disorders. The management of $\mathrm{HLH}$ is aimed at identifying and managing any underlying trigger and controlling the overactive immune system.,

Nearly all patients with HLH present with hepatic manifestations ranging from mild hepatic dysfunction to overt liver failure, and some of these patients might be referred to the pediatric gastroenterologist on the suspicion of severe acute hepatitis or acute liver failure (ALF) primarily. HLH is one of the rarely reported causes of pediatric acute liver failure (PALF). ${ }^{5}$ HLH as a cause of ALF has been reported previously in $2 \%$ of cases in $<3$ years of age, $1 \%$ in $>3$ years of age children, and in $2.7 \%$ of cases of neonates and infants $<90$ days. ${ }^{6}$

Early recognition is imperative to initiate life-saving treatment but is often hampered due to the delay in diagnosis. We report an unusual case from India of PALF and HLH induced by influenza A (H1N1) and respiratory syncytial virus (RSV) infection. The child did not fulfill all the diagnostic criteria of HLH; however, on strong suspicion and available literature was treated on the lines of PALF associated with HLH and responded very well to the treatment.

\section{Case Report}

A previously healthy 22-month-old boy was air transported to our center with high grade fever and vomiting since 10 days, with a history of high-colored urine, encephalopathy, and melena. At initial presentation, he was tachypneic but maintaining 98\% saturation on room air and had a blood pressure of $120 / 70 \mathrm{mmHg}$ (mean arterial pressure of $90 \mathrm{mmHg}$ ). He was sleepy but arousable with brisk motor reflexes (grade 3 hepatic encephalopathy). ${ }^{7}$ He had bilateral crepitations in the chest with a $5-\mathrm{cm}$ nontender hepatomegaly. There was no icterus or splenomegaly. On evaluation, initial blood investigations demonstrated hemoglobin $(\mathrm{Hb})$ of $9.7 \mathrm{~g} / \mathrm{dL}$, total leucocyte count (TLC) of $4.26 \times 10^{3} / \mu \mathrm{L}$ and platelet count of $133 \times 10^{3} / \mu \mathrm{L}$. Liver function tests revealed total serum bilirubin (TSB; $1.41 \mathrm{mg} / \mathrm{dL}$ ), alanine transaminase (ALT; $10,040 \mathrm{U} / \mathrm{L}$ ), aspartate transaminase (AST; 9,925 U/L), total serum protein $(6.1 \mathrm{~g} / \mathrm{dL})$, albumin (3.3 g/dL), international normalized ratio (INR; 1.77$)$, and plasma ammonia $190 \mu \mathrm{g} / \mathrm{dL}$. The child was immediately shifted to the pediatric intensive care unit and managed on the lines of ALF. Repeated workup demonstrated worsening values on day 2 and 3 of admission, with $\mathrm{Hb}(7.2 \mathrm{~g} / \mathrm{dL}), \mathrm{TLC}\left(3.08 \times 10^{3} / \mu \mathrm{L}\right)$, and platelet count $\left(92 \times 10^{3} / \mu \mathrm{L}\right)$ as depicted in - Table 1. Repeated liver function tests also demonstrated worsening with total TSB (3.3 mg/dL), direct bilirubin ( $2.8 \mathrm{mg} / \mathrm{dL})$, ALT (13,370 U/L), AST (4,000 U/L), albumin (3.2 g/dL), and INR (2.2; - Table 1). The peripheral smear did not show any blasts. Lactate dehydrogenase ( $\mathrm{LDH}$ ) value was raised $(6,972 \mathrm{U} / \mathrm{L})$. Renal functions were preserved. An ultrasound of the abdomen depicted hepatomegaly with mild splenic enlargement. Comprehensive workup was initiated for triggers of PALF. Presence of malaria and dengue infection was ruled out. Initial workup for known hepatotropic and nonhepatotropic viruses (Hepatitis A, B, C, D, and E; CMV; and EBV), Wilson disease, and autoimmune disease was negative. On day 2 of admission, he had one episode of generalized tonic-clonic seizures. Lumbar puncture revealed no pleocytosis. However, cerebrospinal fluid protein was elevated $(420 \mathrm{mg} / \mathrm{L}){ }^{8}$ Magnetic resonance imaging brain was normal. In view of fever, cough, and bilateral perihilar infiltrates on chest X-ray, community infectious profile and rapid respiratory pathogen assay was sent, which depicted H1N1 real-time polymerase chain reaction positive for Influenza $A$ and H1N1. RSV was detected in rapid respiratory molecular array. Due to persistent fever with bicytopenia, a strong possibility of HLH was considered. Workup demonstrated markedly elevated serum ferritin $(31,278 \mathrm{ng} / \mathrm{mL})$, hypofibrinogenemia $(149 \mathrm{mg} / \mathrm{dL})$, and normal serum triglyceride $(105 \mathrm{mg} / \mathrm{dL})$. With this clinical setting, HLH was very strongly suspected with possible central nervous system (CNS) involvement, though he did not meet all the required diagnostic criteria of HLH (-Table 2). Cerebrospinal fluid analysis done also demonstrated histiocytes on cerebrospinal fluid (CSF) cytospin, although the bone marrow biopsy did not show any hemophagoctyosis. On evaluation for primary underlying etiology of HLH, genetic testing by exome sequencing (AP3B1, BLOC1S6, CD27, ITK, LYST, PRF1, RAB27A, SH2D1A, SLC7A7, STX11, STXBP2, UNC13D, and XIAP) did not show any evidence of familial HLH.

In view of the devastating immune activation in HLH, systemic immunomodulatory therapy was started. Intravenous dexamethasone was administered at the dose of $10 \mathrm{mg} / \mathrm{m}^{2}$, in addition to oseltamivir. The patient's symptoms improved dramatically after starting immunomodulatory treatment and he made a complete clinical recovery. Recovery of laboratory parameters was noted ( $\mathbf{- T a b l e ~} \mathbf{1}$ ) with complete resolution of coagulopathy and improving counts. The patient was discharged on oral dexamethasone that was tapered over 8 weeks. He remained healthy without a recurrence of $\mathrm{HLH}$ during a 2-year follow-up.

\section{Discussion}

Patients with HLH typically present with varied hepatic manifestations ranging from mild transaminitis to fulminant liver failure. In recent years, HLH presenting as ALF has been noticed; however, the diagnosis is rare and challenging, and mortality remains high. ${ }^{5,6}$ It is therefore crucial to look for underlying HLH as an important differential diagnosis in the etiological workup for ALF. Concurrent cytopenia and elevated levels of serum ferritin with unexplained liver failure should raise a suspicion of $\mathrm{HLH}$ as seen in our previously healthy 22-month-old patient presenting with ALF. ${ }^{8,9}$

A definite diagnosis of HLH is established if patient meets five out of eight criteria as depicted in - Table $2{ }^{3}$ We could not check for sIL-2R or natural killer cell function as it was not feasible. Despite only four criteria being fulfilled in our patient, HLH was still strongly suspected. ${ }^{3}$

HLH is a syndromic diagnosis; all the diagnostic criteria may not be fulfilled at presentation, thus necessitating serial follow-ups. Recent data in children have shown that serum ferritin levels more than $10,000 \mathrm{ng} / \mathrm{mL}$ are $98 \%$ specific for HLH. ${ }^{9}$ The initial marrow examination or tissue biopsies may 
Table 1 Depicting serial investigations of the patient

\begin{tabular}{|l|l|l|l|l|l|l|l|}
\hline & Before admission & Day 1 & Day 2 & Day 3 & Day 7 & Day 10 & On d/c \\
\hline $\mathrm{Hb}(\mathrm{g} / \mathrm{dL})$ & 9.7 & 8.7 & 7.8 & 7.2 & 9.5 & 11.3 & 11.2 \\
\hline $\begin{array}{l}\mathrm{TLC} \\
\left(\times 10^{3} / \mu \mathrm{L}\right)\end{array}$ & 4.26 & 3.71 & 3.51 & 3.08 & 3.87 & 3.93 & 8.72 \\
\hline $\begin{array}{l}\text { Platelet count } \\
\left(\times 10^{3} / \mu \mathrm{L}\right)\end{array}$ & 130 & 92 & 96 & 124 & 122 & 120 & 338 \\
\hline Total serum bilirubin $(\mathrm{mg} / \mathrm{dL})$ & 1.41 & 2.7 & 2.5 & 2.4 & 2.2 & 1.9 & 1.4 \\
\hline AST $(\mathrm{U} / \mathrm{L})$ & 10,040 & 13,370 & 7,682 & 3,880 & 746 & 1,423 & 194 \\
\hline ALT $(\mathrm{U} / \mathrm{L})$ & 9,925 & 4,000 & 3,720 & 2,340 & 1,260 & 1,730 & 464 \\
\hline Ammonia $(\mu \mathrm{g} / \mathrm{dL})$ & 191 & 136 & 87 & 68 & 63 & 56 & 42 \\
\hline Lactate $(\mathrm{U} / \mathrm{L})$ & $\mathrm{NA}$ & 3.3 & 1.8 & 2.0 & 1.3 & 1.9 & 1.2 \\
\hline PT $(\mathrm{sec})$ & 21.8 & 22.5 & 20.5 & 18.6 & 15.8 & 13.8 & 12.2 \\
\hline INR & 1.77 & 2.2 & 2.1 & 1.9 & 1.5 & 1.3 & 1.1 \\
\hline Serum Creatinine $(\mathrm{mg} / \mathrm{dL})$ & 0.9 & 0.8 & 0.8 & 0.7 & 0.8 & 0.7 & 0.7 \\
\hline
\end{tabular}

Abbreviations: ALT, alanine transaminase; AST, aspartate transaminase; $\mathrm{d} / \mathrm{c}$, discharge; $\mathrm{Hb}$, hemoglobin; INR, international normalized ratio; NA, not available; PT, prothrombin time; TLC, total leucocyte count.

Table 2 Diagnostic criteria for hemophagocytic lymphohistiocytosis according to the hemophagocytic lymphohistiocytosis 2004 guideline

\begin{tabular}{|c|}
\hline $\begin{array}{l}\text { The diagnosis of HLH can be established if one of the either } \\
1 \text { or } 2 \text { below is fulfilled. }\end{array}$ \\
\hline 1. A molecular diagnosis consistent with $\mathrm{HLH}$ \\
\hline 2. Diagnostic criteria for HLH fulfilled ( 5 out of 8 criteria below) \\
\hline A. Initial criteria (to be evaluated in all patients with $\mathrm{HLH}$ ) \\
\hline Clinical criteria \\
\hline 1. Fever \\
\hline 2. Splenomegaly \\
\hline Laboratory criteria \\
\hline $\begin{array}{l}\text { 3. Cytopenias (affecting t2 lineages in peripheral blood): anemia } \\
\text { (hemoglobin }<9 \mathrm{gm} / \mathrm{dL} \text { ), thrombocytopenia }\left(<100 \times 10^{3} /\right. \\
\left.\mu \mathrm{L}) \text {, and neutropenia (ANC }<1.0 \times 10^{3} / \mu \mathrm{L}\right)\end{array}$ \\
\hline $\begin{array}{l}\text { 4. Hypertriglyceridemia ( }>265 \mathrm{mg} / \mathrm{dL} \text { ) and/or hypofibrinoge- } \\
\text { nemia (<150 mg/dL) }\end{array}$ \\
\hline Histopathologic criteria \\
\hline $\begin{array}{l}\text { 5. Hemophagocytosis (in bone marrow, spleen, or lymph } \\
\text { nodes). }\end{array}$ \\
\hline No evidence of malignancy \\
\hline B. New diagnostic criteria \\
\hline 6. Low/absent NK cell activity \\
\hline 7. Hyperferritinemia (>500 ng/mL) \\
\hline 8. Increased soluble CD 25 t2400 units/mL \\
\hline
\end{tabular}

Abbreviations: HLH, hemophagocytic lymphohistiocytosis; NK, natural killer; sIL-2R, soluble interleukin-2 receptor.

Note: Adapted from Henter et al. ${ }^{3}$

not always show hemophagocytosis, which may be depicted on serial examinations. A diagnosis of HLH should not be excluded just on the basis of absent hemophagocytosis. ${ }^{10,11}$

CNS involvement has been frequently reported at disease onset in both primary and secondary HLH, with a highly
Table 3 Depicting clinical and laboratory features

\begin{tabular}{|l|}
\hline $\begin{array}{l}\text { Hepatic dysfunction (acute liver failure and hepatic } \\
\text { encephalopathy) }\end{array}$ \\
\hline Respiratory symptoms (cough) \\
\hline Central nervous system symptoms (seizures) \\
\hline Hepatomegaly \\
\hline Anemia $(\mathrm{Hb}<9 \mathrm{~g} / \mathrm{dL}$ ) \\
\hline Thrombocytopenia (platelet $\left.<100 \times 10^{3} / \mu \mathrm{L}\right)$ \\
\hline Neutropenia $\left(\right.$ ANC $\left.<1.0 \times 10^{3} / \mu \mathrm{L}\right)$ \\
\hline Coagulopathy (prolonged $\mathrm{PT}$ and $\mathrm{APTT})$ \\
\hline Elevated liver transaminases $(>60 \mathrm{IU} / \mathrm{L})$ \\
\hline Hyperbilirubinemia $(>2 \mathrm{mg} / \mathrm{dL})$ \\
\hline Hyperferritinemia $(>500 \mu \mathrm{g} / \mathrm{L})$ \\
\hline Hypofibrinogenemia $(<150 \mathrm{mg} / \mathrm{dL})$ \\
\hline Elevated CSF protein $(>300 \mathrm{mg} / \mathrm{L})$ \\
\hline Histiocytes on CSF cytospin \\
\hline High LDH ( $>450 \mathrm{IU} / \mathrm{L})$ \\
\hline
\end{tabular}

Abbreviations: ANC, absolute neutrophil count; aPTT, activated partial thromboplastin time; CSF, cerebrospinal fluid; Hb, hemoglobin; LDH, lactate dehydrogenase; PT, prothrombin time.

variable clinical presentation - Table 3. Overall, CNS disease has been reported in 30 to $73 \%$ of all HLH patients, with seizures being the most common neurological manifestation. CSF pleocytosis, increased protein levels, and presence of abnormal CSF (which has been defined as including pleocytosis, increased CSF protein, or both.) have been reported in nearly 10 to $47 \%, 11$ to $41 \%$, and 16 to $76 \%$ of HLH patients, respectively. ${ }^{12}$

It is interesting to note that over the years HLH has been considered as a controversial indication for liver transplantation. In recently published literature, liver 
transplantation has been reported to be beneficial as a therapeutic modality for children with ALF and secondary HLH for improved survival, with graft and patient survival rates of 60 and $67 \%$, respectively. ${ }^{13}$

The available literature does not offer any consensus on treatment toward CNS involvement in HLH. The majority of published reports describe use of systemic steroids with other immunosuppressants. It has been suggested to withhold intrathecal chemotherapy at the start of therapy in CNS involvement, as in most cases, CNS symptoms improve with systemic therapy. Our patient responded very well to systemic steroids and recovered completely. ${ }^{12}$

To the best of our knowledge, this is the fourth reported case of a successful rescue of PALF associated with HLH without resorting to liver transplantation worldwide till date. The first reported case was a newborn with ALF and HLH triggered by HSV-1, who responded well to high-dose acyclovir and immunosuppression. ${ }^{14}$ The second reported case was a 16 -year-old girl with ALF associated with HLH induced by varicella infection. She was also successfully treated with acyclovir and immunosuppression. ${ }^{15}$ Survival data in older children and adults are sparse, most of whom underwent liver transplantation or expired. 5,6,8 The third reported case was of a 4-year-old child with influenza infection H3N2 who improved with plasmapheresis and antiviral therapy. ${ }^{16}$

\section{Conclusion}

The varied initial presentations and incomplete diagnostic criteria of HLH may often lead to misdiagnosis and delay. Due to rarity, variable presentation, and high mortality of HLH in the context of ALF, it is imperative to keep a low threshold of suspicion for HLH in unexplained ALF for institution of early life-saving therapy.

\section{Authors' Contributions}

R.M. supported in data collection, data analysis, and first draft of manuscript. S.M., N.J., and A.M. contributed in editing and preparing second draft of manuscript. A.S. dedicated in supervision, editing. All authors approved of the final manuscript.

\section{Funding \\ None.}

Conflict of Interest

None declared.

\section{References}

1 Ramos-Casals M, Brito-Zerón P, López-Guillermo A, Khamashta MA, Bosch X. Adult haemophagocytic syndrome. Lancet 2014;383 (9927):1503-1516

2 Canna SW, Behrens EM. Not all hemophagocytes are created equally: appreciating the heterogeneity of the hemophagocytic syndromes. Curr Opin Rheumatol 2012;24(01):113-118

3 Henter JI, Horne A, Aricó M, et al. HLH-2004: diagnostic and therapeutic guidelines for hemophagocytic lymphohistiocytosis. Pediatr Blood Cancer 2007;48(02):124-131

4 Jordan MB, Allen CE, Weitzman S, Filipovich AH, McClain KL. How I treat hemophagocytic lymphohistiocytosis. Blood 2011;118 (15):4041-4052

5 Schneier A, Stueck AE, Petersen B, Thung SN, Perumalswami P. An Unusual Cause of Acute Liver Failure: Three Cases of Hemophagocytic Lymphohistiocytosis Presenting at a Transplant Center. Semin Liver Dis 2016;36(01):99-105

6 Sundaram SS, Alonso EM, Narkewicz MR, Zhang S, Squires RHPediatric Acute Liver Failure Study Group. Characterization and outcomes of young infants with acute liver failure. J Pediatr 2011;159(05):813-818.e1

7 Squires RH Jr. Acute liver failure in children. Semin Liver Dis 2008; 28(02):153-166

8 Renuart AJ, Mistry RD, Avery RA, et al. Reference range for cerebrospinal fluid protein concentration in children and adolescents. Arch Pediatr Adolesc Med 2011;165(07):671-673

9 Allen CE, Yu X, Kozinetz CA, McClain KL. Highly elevated ferritin levels and the diagnosis of hemophagocytic lymphohistiocytosis. Pediatr Blood Cancer 2008;50(06):1227-1235

10 Bode SF, Lehmberg K, Maul-Pavicic A, et al. Recent advances in the diagnosis and treatment of hemophagocytic lymphohistiocytosis. Arthritis Res Ther 2012;14(03):213

11 Rosado FG, Kim AS. Hemophagocytic lymphohistiocytosis: an update on diagnosis and pathogenesis. Am J Clin Pathol 2013; 139(06):713-727

12 Horne A, Wickström R, Jordan MB, et al. How to treat involvement of the central nervous system in hemophagocytic lymphohistiocytosis? Curr Treat Options Neurol 2017;19(01):3

13 Amir AZ, Ling SC, Naqvi A, et al. Liver transplantation for children with acute liver failure associated with secondary hemophagocytic lymphohistiocytosis. Liver Transpl 2016;22 (09):1245-1253

14 Yamada K, Yamamoto Y, Uchiyama A, et al. Successful treatment of neonatal herpes simplex-type 1 infection complicated by hemophagocytic lymphohistiocytosis and acute liver failure. Tohoku J Exp Med 2008;214(01):1-5

15 Zhang LN, Guo W, Zhu JH, Guo Y. Successful rescue of acute liver failure and hemophagocytic lymphohistiocytosis following varicella infection: a case report and review of literature. World J Clin Cases 2018;6(13):659-665

16 Yükselmiş U, Girit S, Çağ Y, Özçetin M. A child with acute liver failure associated with influenza $A$ and resolved with plasma exchange treatment. Hong Kong J Emerg Med 2018;25(05): 281-285 